\title{
Attitude and Motives Towards Corporate Social Responsibility in the Kingdom of Saudi Arabia
}

\author{
Rawan Al Mohanna ${ }^{1} \&$ Lama Al-Kayed ${ }^{1}$ \\ ${ }^{1}$ School of Business, Princess Nourah bint Abdulrahman University, Riyadh, Saudi Arabia \\ Correspondence: Lama Al-Kayed, School of Business, Princess Nourah bint Abdulrahman University, Riyadh, \\ Saudi Arabia. Tel: 966-11-822-3093. E-mail: ltalkayed@ pnu.edu.sa
}

Received: September 17, 2018

Accepted: October 11, 2018

Online Published: October 20, 2018

doi:10.5539/ijef.v10n11p63

URL: https://doi.org/10.5539/ijef.v10n11p63

\begin{abstract}
This paper explores the attitudes of large and small firms' managers toward Corporate Social Responsibility (CSR) in the Kingdom of Saudi Arabia and the motivations behind the implementation of such an initiative. The research revealed a gap in the minute number of studies exploring CSR practices the kingdom's SMEs. There was a further gap in the managers' motives towards CSR within the same region. As a way of responding to the four proposed research questions, the researchers surveyed 52 SME and large firms. Ideally, the results showed that large firms pursue traditional CSR practices and record their activities unlike SMEs, which follow a contemporary approach to CSR, with little regard to recording their activities. In addition, large firms significantly perceive CSR as an obligation, while SMEs rely on their board of management's beliefs. This paper provides an insight for the policymakers to adopt different approaches for large and small firms in their implementation of CSR practices in pursuance of satisfactory reports.
\end{abstract}

Keywords: CSR, large enterprises, small and medium size enterprises, KSA

\section{Introduction}

There is a growing global interest in corporate social responsibility (CSR) by companies, regulators, and investors. The contemporary world has heightened awareness of this concept. The globalization trends have since seen the transformation of many firms in the western world from viewing CSR as a favor to the society to a responsibility of the firm as an exchange for what it has received from society. CSR is internal to the corporation and is vital in directing the plans of the firm and their course of action in respect to the society. CSR of a corporation includes legal, economic, and social expectations that society expects from the organization at any given point in time. CSR is essentially the set of operations that a firm does and which benefits the society (Garas \& ElMassah, 2018). CSR has since attracted global attention as it defines the business-society relationship and is underpinned by the knowledge that any business has other crucial responsibilities that are beyond the continuity and profitability of the business.

\section{CSR in Kingdom of Saudi Arabia (KSA)}

Saudi Arabia is adopting the notion of CSR in its private sector. The government plays a crucial role in consolidating the opportunities and skills that come from the private sector and providing a suitable environment through which the corporate sector can benefit the society. CSR is of great importance in KSA because the country's economy is rapidly opening up and the government is in the process of diversifying its local investments with the aim of minimizing its dependency on the petroleum sector as the core investment (Goyal, 2006). The country through its government policies and adjustments has invested in numerous sectors of the economy including in telecommunications, food production, financial institutions thus changing its status from a net importer of these products and services to being self-sufficient and an exporter in the end. The key issues for CSR in KSA include health and safety standards, improved working environment, good governance, and improving the environment. These areas are common areas of interest by both the corporate sector and the government thus providing opportunities for government-private sector partnerships for society development (Kolk \& van Tulder, 2010).

Companies in KSA are also recognizing the benefits that accrue from engaging in responsible business practices as opposed to just giving towards charity. In turn, the ever-growing corporate appreciation of CSR enhances the 
performance of businesses, which encourages meaningful outcomes that spring from the concerted efforts in KSA. Furthermore, Saudi Arabia is a victim of various challenges with respect to development. The main challenges facing KSA include poverty, unemployment, low quality of life, imbalances in regional development, and water scarcity. These challenges are enough evidence that there is a need for CSR in Saudi Arabia to help the government in the development efforts and combating these challenges (Garas \& ElMassah, 2018). The purpose of this study is to explore the attitudes and the motives towards CSR in Saudi Arabia and the level of awareness of CSR among the key players of Saudi Arabia's corporate sector.

\section{Research Questions}

The kingdom of Saudi Arabia is not only a member of the Gulf Corporation Council (GCC) but is also host to many huge and essential industries such as banking, pharmaceuticals and refining, and health care among others. Over the recent past, most firms in the KSA have started to demonstrate a greater commitment by instituting programs and guidelines towards making CSR a success (Al Yahya \& Fustier, 2011). The main challenge facing these concerted efforts by the firms is the lack of a theoretical and practical framework that will guide the CSR processes to fit into the Saudi context in a manner that is dependable. The key objective of this study is to highlight and explore the gaps that exist in CSR within the Saudi context. The research takes a holistic view of the Saudi area and makes assessments to determine the extent of the penetration of CSR in Saudi firms. Thus, the research questions that guide this exploration process include:

1) What is the degree of the managerial attitudes and awareness towards CSR?

2) To what extent is the CSR policy integration become part of the overall corporate policy?

3) What CSR activities are being implemented by Saudi firms to enhance the environment, the local community, the customers and the employees?

\section{Literature Review}

Corporate social responsibility is mostly considered a western practice, which is anchored on the strong standards and appeal systems of institutions, a phenomenon that is generally weak especially in the developing countries of Asia and Africa. These weak standards continuously pose hurdles along the way to achieving reasonable CSR in developing countries. Western countries are seen to lead while Asian countries lag behind in CSR practices (Garas \& ElMassah, 2018). In the recent years, CSR practices by Saudi Arabia firms have gained importance owing to the rise of privatization, globalization and liberalization practices, the growing consumer expectations, the entry of Multinational Corporations, and the rise of pressure groups that push for the implementation of CSR practices. Saudi Arabia has been on the lead at the state level topping the list of humanitarian aid and donations. In 2007, the Kingdom of Saudi Arabia donated \$158 million on the grounds of playing a part in the United Nations humanitarian mission. This was followed by their $\$ 50$ million donations to Haiti in 2010 under the United Nations Emergency response Fund (Al Yahya \& Fustier, 2010). One of its large contributions is the 2008 donation of $\$ 500$ to the world food program making history as one of the ever largest contributions to the WFP kitty (World Food Program).

Despite its active involvement in the global humanitarian practices, KSA continues to lag behind with regard to its internal social responsibility by the corporate sector. There is a need for an efficient and effective system that will provide the coordination of the key CSR activities in a bid to strategically communicate and position them, thus furthering the international standing of the kingdom as far as CSR is concerned. While there is a rise in awareness about CSR in the Middle East, still most of the CSR activities are performed by foreign companies and businesses, while little or no initiatives have been taken by local businesses (Garas \& ElMassah, 2018). It is vital that the local businesses and companies take an active role in CSR because the World Bank has made findings that economic growth and sustainability in the Middle East is a subject of good governance and accountability (Kolk \& van Tulder, 2010).

Today, the developed economies have laid more emphasis and the recognition of CSR is no longer an optional thing. Firms in these countries no longer see CSR as an optional thing or an indicator of their goodwill or even their profitability. Firms are not only responsible for their conduct but also for their performance as well (Basdekidou, 2017). It is no longer enough to have appealing mission statements and a set of ethical codes to guide the behavior of the firm. Rather, firms have found it necessary to incorporate ethics and CSR as part of their fabric. In predominantly western economies, the integration of CSR comes in various angles namely the ethical values of a firm and the impact it has on the earning management, facilitating green marketing, emphasis on sustainability, good corporate citizenship, and environmental issues from the institution perspective (Kolk \& van Tulder, 2010). Under the operational standpoint, firms play a key role in incorporating social characteristics 
into their goods such as coming up with environmentally friendly technologies, adopting and implementing human resource practices that are progressive through employee empowerment, humane working environments, and fostering good environmental management practices through recycling of wastes, and cutting down on emissions.

Carrol (1991) explored the nature of CSR with an eye toward understanding its component parts. The intention was to characterize the firm's CSR in ways that might be useful to executives who wish to reconcile their obligations to their shareholders with those to other competing groups claiming legitimacy. Carrol (1991) has set fourth a four-part conceptualization of CSR with the idea that corporations have not only economic and legal obligations, but ethical and discretionary (philanthropic) responsibilities as well. These four categoies or components of CSR might be depicted as a pyramid. Concequently, much of the academic debate on CSR has centred on whether small and medium enterprises (SMEs hereafter) are more or less socially responsible than large corporations (Fitjar, 2011). Several studies found a positive correlation between firm size and CSR work (Vives et al., 2005, Brammer \& Millington, 2006 fom Fitjar, 2011). Other studies claim that such positive connection is spurious resulting mainly from the tendency for SMEs to underreport their CSR activities. Mostly, SMEs are not aware of CSR activities they actually engage in, they do not tend to codify their CSR activities in the way of agreements, organisations or standards, and they prefer to use informal instruments to convey their CSR activities to the public rather than producing CSR reports (Fitjar, 2011). Although general impression is that large corporations are more advanced at implementing CSR compared to SMEs (Campbell, 2007; McWilliams \& Siegel, 2001 from Baumann-Pauly, Wickert, Spence, \& Scherer, 2013), scholars focusing on CSR in SMEs have not reached a consensus on whether SMEs are better or worse equipped to organize CSR than large firms.

CSR research has demonstrated that when it comes to CSR, SMEs are not 'little big firms' (Tilley, 2000 from Fitjar, 2011) and should not be treated as such. A study by Baumann-Pauly, Wickert, Spence, and Scherer (2013) suggests that smaller firms are not necessarily less advanced in organizing CSR than large firms. Many SMEs however, perceive CSR as burden, they worry that they will not reach their clients and suppliers' standards without being competitively deprived of their real and potential markets (Maloni \& Brown, 2006). Nevertheless, many SMEs adopt CSR because of the personal beliefs and values of the founders (Vallentin \& Morsing, 2008). On the other hand, large corporations are obliged to include financial and non-financial key performance indicators in their annual report in some countries or to follow the business best practices in their codes of conduct. Considering that, there is evidence that the performance of a corporation is positively affected by intangible assets such as contributing to the community (Castaldo \& Perrini, 2004).

\section{CSR in the Kingdom of Saudi Arabia}

Firms in the Middle East region ought to develop policies to govern CSR so that the local corporations take the lead in aiding the development agenda of the KSA through promoting good education, housing, health, and environmental conservation practices. The governments in these areas feel that it is their sole responsibility to develop and contribute to the social sectors such as in health, education and environmental conservation, thus closing out any efforts by the corporate sector to contribute (Magbool, 2015). There are three suggestions through which CSR is e enacted in KSA. The first one is through public-private partnerships (PPP), the second is through incentives and award for the best CSR performances, and finally through providing social services and amenities such as vocational training institutions, colleges, and schools (Singh, 2013). The Qatar National Bank (QNB) is one of the leading financial services providers in Qatar and is a key player in CSR. The bank chairman notes that "We believe that successful organizations must always aim to be the best they can be - and more. If they are to be effective leaders, they must take their role one step further and give generously to the community of people who fuel their success." (Magbool, 2015) The bank also publishes its annual CSR activities in the bank's website with the aim of helping other banks, stakeholders, and even foreigners that it gears towards ensuring that the community and the entire country realize their maximum potential. In overall, the literature and evidence derived from both the GCC region and the western regions provide us with a firm foundation to aid this research, as it aims to obtain first-hand information into the view of CSR by countries in the KSA context. In addition, it aids us in coming up with a normative model that can be implemented by managers of firms in KSA.

\section{Study Design and Methodology}

CSR awareness within the KSA is still in its early stages. While we can make conclusions based on experiences gained from other GCC countries, the objective of this study demands that we should, first of all, understand the perspectives that Saudi managers hold towards CSR. For this reason, our research was conducted through a survey method. The survey was distributed to Saudi based firm managers as respondents who are well aware of CSR policies in their respective organizations. Therefore, a self-administered survey, which was initially written 
in English but later translated into Arabic, was administered to the target 120 managers who operate in the various economic sectors of the Saudi economy specifically in Jeddah. The respondents of this study were recruited in two approaches namely using the local chamber of commerce directories and word of mouth. In addition, the respondents were informed of the purpose for conducting this research and therefore received informed consent from the participants. This process ensures that the highest levels of ethics and integrity are maintained. Three research assistants got recruited to facilitate the processof dropping the surveys to the various working places of the managers. The assistants later returned and collected the completed surveys after a period of one week. Of the total number of distributed surveys, only 78 filled surveys were returned making a $65 \%$ response rate. The following is the demographic profile of the total sample $n=78$.

Table 1. CSR demographic profile

\begin{tabular}{ll}
\hline Gender & Percentage \% \\
\hline Male & 69.8 \\
Female & 30.2 \\
Industry & \\
Manufacturing & 38.8 \\
Trade & 45.6 \\
Services & 23.5 \\
Managerial level & \\
Senior management & 13.6 \\
Middle management & 27.3 \\
Junior management & 33.1 \\
Staff & 26 \\
Employees population & \\
$<500$ & 33.8 \\
501-1000 & 14.7 \\
>1000 & 51.5 \\
Level of education & \\
High school and less & 13.2 \\
College graduate & 51.5 \\
Bachelor's degree & 35.3 \\
In-house CSR department & \\
Yes & 39.7 \\
No & 60.3 \\
CSR dept. status & \\
Part of public relations & 40.5 \\
Under marketing & 3.3 \\
Under external affairs & 51.5 \\
Under other departments & 4.7 \\
\hline
\end{tabular}

\section{Results and Discussion}

As Table 2 shows, Saudi Arabian managers are already familiar with the notion of CSR. A more significant percentage have a positive attitude towards its adaption. The managers, however, doubt the receptiveness of the top management to the idea of CSR in their firms. Managers attribute the low adaption of CSR by Saudi Arabia firms to the lack of organization-wide support for CSR and the lack of proper and clear organizational policies that govern such practices (García-Meca \& Pucheta-Martínez, 2017). The goal is to make more managers aware of the benefits of engaging in CSR. Furthermore, there is a need for policy backed executive management CSR frameworks that will be initiated and communicated throughout the firm.

Table 2. CSR awareness by Saudi managers

\begin{tabular}{lll}
\hline Factor & Mean score & Standard deviation \\
\hline I know about the concept of CSR & 4.15 & .72 \\
Our firm actively enforces CSR & 3.39 & 1.39 \\
We find CSR to be important to us & 4.37 & .79 \\
CSR is good for the reputation of our firm & 4.31 & .90 \\
We invest annually to support CSR activities & 3.57 & 1.01 \\
It is our responsibility to give back to the community in the form of CSR & 3.88 & 1.07 \\
\hline
\end{tabular}




\subsection{Extent of Integration of CSR and Corporate Policies}

From the tabulated data, it is evident that the Saudi managers are not very confident that social goals have been fused into their corporate strategic goals so that they work together towards realizing the goals of the firm. About 50 percent of all the sample firms have CSR function that is not older than 5-years. This means that CSR in the KSA firms is still in its early stages. Most firms in KSA do not have a clear policy that guides the organization on how to spend on CSR. In addition, it is evident that most organizations don't have an organizational support culture to support the activities geared towards CSR.

Table 3. Social goals integration

\begin{tabular}{lcc}
\hline Activity & Mean & Standard deviation \\
\hline Our firm has clear policies on how to spend on CSR & 2.65 & 1.28 \\
Our organization enjoys organization-wide support from all the members towards CSR in our community & 2.97 & 1.32 \\
We have incorporated social goals as part of the strategic goals in the firm & 3.53 & 1.18 \\
Social goals do not conflict with our firms strategic goals hence they are important to us & 3.10 & 1.11 \\
\hline
\end{tabular}

\subsection{CSR Activities}

From the results in Table 4, it is evident that, although the managers of firms in Saudi Arabia have positive intentions towards taking good care of the surrounding external environment, the organizational lack clear policies and frameworks geared towards preserving the environment except that from the national government. The CSR activities are less formalized thus less activity by the private corporations (García-Meca \& Pucheta-Martínez, 2013).

Table 4. Attitudes towards the natural environment

\begin{tabular}{lcc}
\hline Activity & Mean & Standard deviation \\
\hline Environment preservation is part of our priorities & 3.14 & 1.19 \\
It is our responsibility not to harm the environment & 4.33 & .77 \\
We are compliant with the national environmental law & 4.18 & .06 \\
We conduct regular assessments on the impact of our firm on the environment & 2.54 & 1.21 \\
It's our policy that our suppliers must comply to the set environmental guidelines & 3.11 & 1.21 \\
\hline
\end{tabular}

\subsection{Community-Based Activities}

In Table 5, we find that the majority of the CSR activities are not formalized and are primarily in the scope of the immediate operational environment of the firm. Despite the willingness to carry out community-based activities to foster development in their regions, the firms are hardly participating in the development agenda of the community effectively. Most of the organizations do not provide charitable donations to their immediate communities.

Table 5. Community activities

\begin{tabular}{lcc}
\hline Activity & Mean & Standard deviation \\
\hline We engage in community activities as a firm & 3.72 & 1.05 \\
We provide charitable donations to the community & 3.51 & 1,18 \\
Our firm feels a sense of responsibility for the community & 3.99 & .93 \\
We sponsor many projects yearly within the local community & 3.81 & 1.12 \\
Community development is part of our agenda & 3.91 & .94 \\
We support well-being campaigns in our community & 3.47 & 1.19 \\
\hline
\end{tabular}

\section{Conclusion}

The goal of this exploratory study was to show the CSR status among the SME's in KSA. From the results derived from multiple managers who were also the sample participants of this study indicates that even though the managers have a positive attitude and higher acceptance rate for CSR, yet there is a disconnection between the attitudes of the managers and those of the executive management. The concept of CSR is still in its infancy in 
most of the Firms in the Kingdom of Saudi Arabia. The CSR concept is still new in, and this reflects on the development stage of the private firms in the kingdom. CSR practices in Saudi Arabia are seen to incline towards a classical and philanthropic affair rather than being part of the strategic plan of the firms. This finding indicates that there is a small amount of educated western managers in the Saudi Arabia region who understand the importance of CSR to the organization as opposed to being a classical activity to demonstrate the philanthropic nature of the firm. It is also noteworthy that Saudi Arabia managers are willing and have a positive attitude towards adopting a modernly defined CSR practice. This attitude should, however, be backed with executive management driven CSR policies and initiatives that should be introduced, and communicated to all the organizational levels.

\section{References}

Al Yahya, K., \& Nathalie, F. (2011). Saudi Arabia as a Humanitarian Donor: High Potential, Little Institutionalization. SSRN Electronic Journal.

Basdekidou, V. A. (2017). Green Entrepreneurship \& Corporate Social Responsibility: Comparative and Correlative Performance Analysis. International Journal of Economics and Finance, 9(12). https://doi.org/10.5539/ijef.v9n12p1

Baumann-Pauly, D., Wickert, C., Spence, L. J., \& Scherer, A. G. (2013). Organizing corporate social responsibility in small and large firms: Size matters. Journal of Business Ethics, 115(4), 693-705. https://doi.org/10.1007/s10551-013-1827-7

Brammer, S., \& Millington, A. (2006). Firm Size, Organizational Visibility and Corporate Philanthropy: An Empirical Analysis. Business Ethics: A European Review, 15(1), 6-18. https://doi.org/10.1111/j.1467-8608.2006.00424.x

Campbell, J. (2007). Why Would Corporations Behave in Socially Responsible Ways? An Institutional Theory of Corporate Social Responsibility. The Academy of Management Review, 32(3), 946-967. https://doi.org/10.5465/amr.2007.25275684

Carroll, A. B. (1991). The Pyramid of corporate social responsibility: Toward the moral management of $\begin{array}{lllll}\text { organizational stakeholders, } & \text { Business } & \text { Horizons, } & 34(4), & 39-48 .\end{array}$ https://doi.org/10.1016/0007-6813(91)90005-G

Castaldo, S., Perrini, F., Misani, N., \& Tencati, A. (2009). The missing link between corporate social responsibility and consumer trust: the case of fair trade products. Journal of Business Ethics, 84(1), 1-15. https://doi.org/10.1007/s10551-008-9669-4

Fitjar, R. (2011). Little big firms? Corporate social responsibility in small businesses that do not compete against big ones. Business Ethics: A European Review, 20(1), 30-44. https://doi.org/10.1111/j.1467-8608.2010.01610.x

Garas, S., \& Suzanna, E. (2018). Corporate Governance and Corporate Social Responsibility Disclosures. Critical Perspectives on International Business, 14(1), 2-26. https://doi.org/10.1108/cpoib-10-2016-0042

García-Meca, E., \& Pucheta-Martínez, M. C. (2017). How Institutional Investors On Boards Impact On Stakeholder Engagement And Corporate Social Responsibility Reporting. Corporate Social Responsibility and Environmental Management, 25(3), 237-249. https://doi.org/10.1002/csr.1451

Goyal, A. (2006). Corporate Social Responsibility as a Signalling Device for Foreign Direct Investment. International Journal of the Economics of Business, 13(1), 145-163. https://doi.org/10.1080/13571510500520077

Kolk, A., \& Rob, van T. (2010). International Business, Corporate Social Responsibility, and Sustainable Development. International Business Review, 19(2), 119-125. https://doi.org/10.1016/j.ibusrev.2009.12.003

Magbool, S. (2015). An Overview of CSR Programs in Saudi Arabia with Reference To Select Organizations. International Journal of Human Resource Studies, 5(2). https://doi.org/10.5296/ijhrs.v5i2.7753

Maloni, M. J., \& Brown, M. E. (2006). Corporate social responsibility in the supply chain: an application in the food industry. Journal of Business Ethics, 68(1), 35-52. https://doi.org/10.1007/s10551-006-9038-0

Singh, R. K. (2013). Corporate Social Responsibility: A Business Solution for Sustainable and Inclusive Development. Prabandhan: Indian Journal of Management, 6, 12.

Torres, C., Garcia-French, M., Hordijk, R., Nguyen, K., \& Olup, L. (2012). Four Case Studies on Corporate Social Responsibility: Do Conflicts Affect a Company Corporate Social Responsibility Policy? Utrecht Law 
Review, 8(3), 51-73. https://doi.org/10.18352/ulr.205

Trong, T. L. (2012). Corporate Social Responsibility, Ethics, and Corporate Governance. Social Responsibility Journal, 8(4), 547-560. https://doi.org/10.1108/17471111211272110

Vallentin, S., \& Morsing, M. (2008). Social responsibility in Danish SMEs: Mapping the territory. Copenhagen: Børsen Forlag.

Vives, A. (2006). Social and Environmental Responsibility in Small and Medium Enterprises in Latin America. Journal of Corporate Citizenship, 21, 39-50. https://doi.org/10.9774/GLEAF.4700.2006.sp.00006

Wickert, C., Scherer, A. G., \& Spence, L. J. (2013). Implementing and Communicating Corporate Social Responsibility: Implications of Firm Size and Organizational Cost. University of Zurich, Institute of Business Administration, UZH Business, Working Paper. 339. https://doi.org/10.2139/ssrn.2342214

World Food Program. L'Aquila" Joint Statement on Global Food Security L'Aquila Food Security Initiative (AFSI). Food Security, 1(3), 235-237. https://doi.org/10.1007/s12571-009-0035-x

\section{Copyrights}

Copyright for this article is retained by the author(s), with first publication rights granted to the journal.

This is an open-access article distributed under the terms and conditions of the Creative Commons Attribution license (http://creativecommons.org/licenses/by/4.0/). 